\title{
Efektivitas Latihan Penguatan terhadap Kemampuan Fungsional Anggota Gerak Atas pada Pasien Strok Iskemi Fase Subakut
}

\author{
Cice Tresnasari, ${ }^{1}$ Andi Basuki, ${ }^{2}$ Irma Ruslina Defi ${ }^{3}$ \\ ${ }^{1}$ Bagian Ilmu Kedokteran Fisik dan Rehabilitasi, Fakultas Kedokteran, Universitas Islam Bandung, Bandung, \\ Indonesia, ${ }^{2}$ Departemen Ilmu Penyakit Saraf, ${ }^{3}$ Departemen Ilmu Kedokteran Fisik dan Rehabilitasi, \\ Fakultas Kedokteran, Universitas Padjadjaran/RSUP Dr. Hasan Sadikin, Bandung, Indonesia
}

\begin{abstract}
Abstrak
Strok merupakan penyakit dengan gejala utama kelemahan satu sisi tubuh. Kelemahan anggota gerak atas (AGA) menyebabkan penurunan kemampuan fungsionalnya. Kekuatan adalah salah satu indikator performa fungsional anggota gerak atas. Tujuan penelitian ini mengetahui efektivitas latihan penguatan anggota gerak atas terhadap peningkatan kekuatan dan kemampuan fungsional anggota gerak atas pada pasien strok iskemi fase subakut dengan menggunakan bola dan pita elastik. Rancangan penelitian adalah eksperimental dan dilaksanakan di Departemen Ilmu Kedokteran Fisik dan Rehabilitasi, RSUP Dr. Hasan Sadikin Bandung periode Desember 2013-Juli 2014. Subjek terdiri atas 21 pasien strok iskemi fase subakut berusia 40-59 tahun. Latihan penguatan dengan pita dan bola elastik dilakukan oleh semua subjek, 3 kali seminggu selama 6 minggu, 2 set setiap latihan, dan 8 repetisi setiap set. Sebelum, setelah 2 minggu, 4 minggu, dan 6 minggu latihan dinilai kekuatan dan fungsi anggota gerak atas. Hasil menunjukkan bahwa latihan penguatan meningkatkan kekuatan anggota gerak atas ( $<<0,001)$ dan meningkatkan fungsi anggota gerak atas ( $<<0,001)$. Simpulan, latihan penguatan anggota gerak atas dengan pita dan bola elastik efektif meningkatkan kekuatan dan fungsi anggota gerak atas pada pasien strok iskemi fase subakut.
\end{abstract}

Kata kunci: Kekuatan anggota gerak atas, kemampuan fungsional, latihan penguatan, strok iskemi subakut

\section{The Effectiveness of Strengthening Exercises on Upper Limbs Functional Ability of Subacute Phase Ischemic Stroke Patients}

\begin{abstract}
Stroke is a disease with the primary symptoms of weakness. The weakness of the upper limbs caused a decrease in functional ability. Strength is one indicator of upper limb functional performance. The purpose of this study was to determine the effectiveness of upper limb strengthening exercises to increase strength and functional ability of upper limbs in patients with subacute phase ischemic stroke using elastic band and balls. The study was conducted using experimental method, performed at the Medical Rehabilitation Division, Dr. Hasan Sadikin General Hospital Bandung from December 2013 to July 2014. Subjects consisted of 21 patients with ischemic stroke subacute phase aged 40-59 years. The strengthening exercises with elastic band and elastic ball were done by all subjects, 3 times a week, for 6 weeks. Each exercise consisted of 2 sets with 8 repetition of each set. Assessment of the strength and upper limbs function done before, after 2 weeks, 4 weeks and 6 weeks of strengthening exercises. Results showed that strengthening exercises increases the strength of the upper limbs $(\mathrm{p}<0.001)$ and increases the upper limbs function $(\mathrm{p}<0.001)$. Conclusions, upper limbs exercise strengthening with elastic band and elastic ball effectively increased the strength and upper limb function in ischemic stroke subacute phase patients.
\end{abstract}

Key words: Functional abilities, ischemic stroke subacute, strength of the upper limbs, strengthening exercises

Received: 1 March 2017; Revised: 28 August 2017; Accepted: 19 September 2017; Published: 27 December 2017

Korespondensi: Cice Tresnasari, dr., Sp.K.F.R., M.Kes. Bagian Ilmu Kedokteran Fisik dan Rehabilitasi, Fakultas Kedokteran, Universitas Islam Bandung. Jln. Tamansari No. 22, Bandung 40116, Jawa Barat, Indonesia. Telepon: (022) 4203368. Faksimile: (022) 4231213. HP: 081320286060. E-mail: ctresnasari@gmail.com 


\section{Pendahuluan}

Strok merupakan defisit neurologis fokal atau global yang terjadi mendadak, menetap lebih dari 24 jam atau berakhir dengan kematian, disebabkan semata-mata oleh gangguan pada pembuluh darah otak. ${ }^{1}$ Prevalensi strok di dunia menurut World Health Organization sebanyak 30,7 juta orang (tahun 2004), sedangkan di Asia Tenggara sebanyak 4,5 juta orang. ${ }^{2}$ Berdasar atas Riset Kesehatan Dasar tahun 2007, prevalensi strok di Indonesia sebanyak 8,3/1.0oo penduduk, prevalensi di Jawa Barat 9,3/1.00o penduduk. ${ }^{3}$ Di RSUP Dr. Hasan Sadikin Bandung, angka kejadian strok sebanyak 832 kasus (tahun 2008), 938 kasus (tahun 2009), dan 996 kasus (tahun 2010). ${ }^{4}$ Strok memerlukan biaya perawatan yang tidak sedikit. ${ }^{5}$

Pada orang tua, strok merupakan penyebab disabilitas kedua setelah demensia, sedangkan di negara berkembang strok menjadi penyebab utama disabilitas pada orang dewasa. ${ }^{2}$ Disabilitas pascastrok berakibat pada kualitas hidup yang rendah. ${ }^{6}$ Gangguan motorik utama penyebab disabilitas adalah hemiplegia. ${ }^{7}$ Kelemahan pada anggota gerak atas (AGA) menyebabkan 40\% pasien strok tidak pernah menggunakan anggota gerak atasnya secara fungsional dalam aktivitas sehari-hari sehingga dapat menurunkan kualitas hidup. ${ }^{8}$ Kemampuan melakukan aktivitas seharihari berhubungan dengan kekuatan AGA. ${ }^{9}$ Pada strok, kekuatan AGA pada sisi paretik merupakan indikator kuat performa AGA dalam aktivitas sehari-hari. ${ }^{10}$

Pendekatan rehabilitasi untuk memperbaiki performa AGA dilaksanakan dengan latihan penguatan, lingkup gerak sendi, keseimbangan, kontrol postural, dan latihan berorientasi pada tugas. ${ }^{11}$ Salah satu alat latihan penguatan adalah pita dan bola elastik. Alat ini bentuknya kecil, mudah dibawa, cukup murah, dan sesuai untuk latihan penguatan oleh karena memiliki tingkat elastisitas berbeda-beda. ${ }^{12}$

Pada tahun 2003, Duncan dkk. ${ }^{13}$ melakukan penelitian pada pasien strok usia di atas 50 tahun dengan lama menderita strok 30-150 hari yang diberi latihan penguatan AGA menggunakan pita elastik merupakan bagian dari rangkaian beberapa program intervensi lain berupa latihan fleksibilitas, keseimbangan, ketahanan, latihan penguatan, dan latihan fungsional anggota gerak bawah 90 menit per hari, 3 kali seminggu selama 12 sampai 14 minggu. Latihan penguatan AGA berupa fleksi dan rotasi eksternal bahu, fleksi dan ekstensi siku, serta ekstensi pergelangan tangan. Hasil penelitian ini menunjukkan tidak terjadi peningkatan signifikan kekuatan menggenggam dan juga peningkatan fungsi motorik. Fungsi motorik AGA menurut Wolf motor function test meningkat hanya pada pasien dengan fungsi AGA lebih baik sebelum intervensi. Penelitian ini tidak spesifik untuk menilai pengaruh latihan penguatan terhadap kekuatan dan fungsi AGA karena latihan penguatan menjadi salah satu dari rangkaian program intervensi, termasuk latihan fleksibilitas, serta ketahanan dan juga latihan fungsional. Latihan fleksibilitas dan ketahanan dapat memberikan pengaruh terhadap kekuatan dan fungsi AGA.

Penelitian lain oleh Winstein dkk. ${ }^{15}$ dilakukan pada pasien strok usia 29-76 tahun dengan lama menderita strok 2 hari sampai 35 hari. Dalam penelitian ini latihan penguatan menggunakan pita dan bola elastik dilakukan selama 1 jam per hari, 5 kali seminggu selama 4-6 minggu. Hasil menunjukkan bahwa latihan penguatan AGA signifikan mampu meningkatkan kekuatan isometrik bahu, siku dan juga pergelangan tangan, namun tidak signifikan mampu meningkatkan kekuatan menggenggam dan juga fungsi motorik. Fungsi motorik dinilai dengan Fugl-Meyer motor scores. Latihan penguatan dilakukan 5 kali per minggu. Hal ini dapat menimbulkan masalah pada kepatuhan pasien dan berkurangnya masa pemulihan setelah latihan. Menurut American College of Sports Medicine (ACSM) latihan untuk satu kelompok otot yang sama dilakukan dengan jarak minimal 48 jam untuk memberi waktu cukup bagi pemulihan otot. ${ }^{15}$ Sampai saat ini di Indonesia belum ada penelitian mengenai efektivitas latihan penguatan AGA menggunakan pita dan bola pada pasien strok.

Berdasar atas hal tersebut perlu dilakukan penelitian melibatkan subjek orang Indonesia yang menilai efektivitas latihan penguatan AGA mempergunakan pita dan bola elastik sebagai latihan inti. Frekuensi latihan 3 kali seminggu memberikan kesempatan untuk pemulihan otot setelah dilakukan latihan sebelumnya. Penilaian fungsi pada penelitian ini menggunakan Chedoke arm and hand activity inventory-9 (CAHAI-9) yang khusus menilai kemampuan fungsional AGA pada pasien strok dengan menilai kemampuan membuka toples kopi, kemampuan mengontak 108 , membuat garis-garis lurus mempergunakan penggaris, menuangkan segelas air, memeras pakaian basah, mengancingkan 5 buah kancing, mengeringkan punggung dengan menggunakan 
handuk, meletakkan pasta gigi di sikat gigi, dan memotong lilin mainan.

\section{Metode}

Subjek dipilih berdasarkan atas kriteria inklusi: hemiparesis strok iskemi fase subakut, serangan strok pertama, usia 40 tahun sampai dengan usia 59 tahun, mampu memahami perintah lisan, tulisan, dan isyarat dengan mini-mental state examination (MMSE) >23, kekuatan motorik 2-3 pada AGA yang paresis, pasien dengan risiko rendah dan sedang berdasar atas ACSM. Pasien dapat bekerja sama serta bersedia menjadi subjek penelitian dengan mengisi dan menandatangani formulir persetujuan setelah diberi penjelasan atau informed consent; dieksklusi bila memiliki gangguan penglihatan serta juga pendengaran sehingga tidak dapat mengikuti prosedur latihan, memiliki gangguan muskuloskeletal di daerah AGA sehingga tidak dapat melakukan prosedur latihan, pasien dengan risiko tinggi berdasar atas ACSM, spastisitas AGA dengan skala modifikasi Ashworth 3. Subjek dikeluarkan dari penelitian bila tidak melakukan latihan dua kali berturutturut.

Rancangan penelitian adalah eksperimental. Analisis pengaruh latihan pada penguatan AGA dilakukan dengan menggunakan uji Friedman. Penelitian ini telah diuji dan dinyatakan layak untuk dilaksanakan oleh Komisi Etik Penelitian Kesehatan, Fakultas Kedokteran, Universitas Padjadjaran melalui surat Nomor: 510/UN6. C2.1.2/KEPK/PN/2O13.

\section{Hasil}

Diperoleh 21 subjek dengan jumlah laki-laki lebih

\section{Tabel 1 Karakteristik Subjek Penelitian}

\begin{tabular}{lrc}
\hline Karakteristik & n=21 & Rata-rata \pm SB \\
\hline Usia (tahun) & & $55,95 \pm 3,59$ \\
Jenis kelamin & & \\
$\quad$ Laki-laki & 12 & \\
$\quad$ Perempuan & 9 & \\
Indeks massa tubuh & & $22,85 \pm 2,76$ \\
$\quad\left(k g / \mathrm{m}^{2}\right)$ & & \\
Lokasi iskemi & & \\
$\quad$ Hemisfer kanan & 6 & \\
$\quad$ Hemisfer kiri & 15 & \\
\hline SB=simpang baku & &
\end{tabular}

banyak. Selama penelitian tidak ada drop out. Sebagian besar subjek mengalami iskemi pada hemisfer kiri (Tabel 1).

Hasil analisis uji Friedman dengan derajat kepercayaan 95\% menunjukkan bahwa secara statistik terdapat perbedaan kekuatan bermakna antara fleksi bahu, ekstensi bahu, fleksi siku, ekstensi siku, fleksi pergelangan tangan, ekstensi pergelangan tangan, menggenggam dan skor CAHAI-9 pasien hemiparesis strok fase subakut sebelum dan setelah latihan penguatan 2 minggu, 4 minggu, dan 6 minggu ( $\mathrm{p}<0,001$; Tabel 2).

Median skor CAHAI-9 sebelum dilaksanakan latihan adalah 47. Nilai ini meningkat signifikan setiap 2 minggu. Skor CAHAI-9 setelah latihan 2 minggu meningkat menjadi 56 , setelah latihan 4 minggu menjadi 61, sedangkan setelah latihan 6 minggu menjadi 63 (Gambar).

\section{Pembahasan}

Sebagian besar subjek adalah laki-laki dengan rata-rata usia 55,95 tahun. Keadaan ini sesuai dengan data di Indonesia bahwa pada umumnya strok mengenai usia di atas 40 tahun dan hasil penelitian oleh Koton dkk. ${ }^{16}$ bahwa usia ratarata pasien strok di Amerika adalah 54,1 tahun. Menurut penelitian oleh Siddique dkk. ${ }^{17}$ di Dhaka $53,75 \%$ pasien strok iskemi berusia 51-6o tahun dengan jumlah pasien laki-laki lebih banyak. Penelitian oleh Picelli dkk. ${ }^{18}$ menunjukkan dari 39 subjek pasien strok, 24 orang adalah laki-laki.

Pada penelitian ini sebagian besar subjek memiliki lesi pada hemisfer kiri. Hal ini sesuai dengan penelitian Picelli dkk. ${ }^{18}$ bahwa 21 dari 39 orang pasien strok memiliki lesi pada hemisfer kiri dan penelitian Gjelsvik dkk. ${ }^{19}$ bahwa $56 \%$ pasien strok berusia 27-93 tahun memiliki lesi pada hemisfer kiri. Indeks massa tubuh rata-rata subjek dalam penelitian ini adalah 22,85. Nilai itu

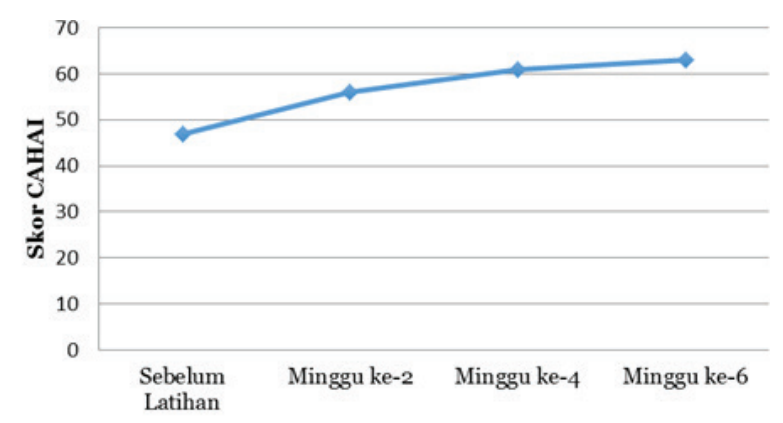

Gambar Grafik Nilai Median Skor CAHAI-9 
Tabel 2 Kekuatan Anggota Gerak Atas dan Skor CAHAI-9 Sebelum dan Setelah Latihan

\begin{tabular}{|c|c|c|c|c|c|}
\hline \multirow[b]{2}{*}{ Karakteristik } & \multicolumn{4}{|c|}{ Waktu Pengukuran Kekuatan } & \multirow[b]{2}{*}{$\mathbf{p}$} \\
\hline & $\begin{array}{l}\text { Sebelum } \\
\text { Latihan } \\
\text { Median } \\
\text { (Min.-Maks.) }\end{array}$ & $\begin{array}{c}2 \text { Minggu } \\
\text { Median } \\
\text { (Min.-Maks.) }\end{array}$ & $\begin{array}{c}4 \text { Minggu } \\
\text { Median } \\
\text { (Min.-Maks.) }\end{array}$ & $\begin{array}{c}6 \text { Minggu } \\
\text { Median } \\
\text { (Min.-Maks.) }\end{array}$ & \\
\hline $\begin{array}{l}\text { Kekuatan fleksi } \\
\text { bahu (kg) }\end{array}$ & $\begin{array}{l}2,25 \\
(1-6)\end{array}$ & $\begin{array}{c}3 \\
(1,25-7,5)\end{array}$ & $\begin{array}{c}3,5 \\
\left(1,5^{-11,25)}\right.\end{array}$ & $\begin{array}{c}3,75 \\
(1,5-11,5)\end{array}$ & $<0, \mathrm{OO1}^{*}$ \\
\hline $\begin{array}{l}\text { Kekuatan ekstensi } \\
\text { bahu (kg) }\end{array}$ & $\begin{array}{c}3,5 \\
(2-6,75)\end{array}$ & $\begin{array}{c}4 \\
(2,5-7,75)\end{array}$ & $\begin{array}{c}4,5 \\
\left(2,5^{-8,75)}\right.\end{array}$ & $\begin{array}{c}4,5 \\
\left(2,75^{-11}\right)\end{array}$ & $<0,001^{*}$ \\
\hline $\begin{array}{l}\text { Kekuatan fleksi } \\
\text { siku (kg) }\end{array}$ & $\begin{array}{c}3 \\
(1,25-5)\end{array}$ & $\begin{array}{c}3,5 \\
\left(1,25^{-7,5)}\right.\end{array}$ & $\begin{array}{c}4 \\
\left(1,25^{-9,5)}\right.\end{array}$ & $\begin{array}{c}4,25 \\
\left(1,5^{-10}\right)\end{array}$ & $<0,001^{*}$ \\
\hline $\begin{array}{l}\text { Kekuatan ekstensi } \\
\text { siku (kg) }\end{array}$ & $\begin{array}{r}2,25 \\
(1-5)\end{array}$ & $\begin{array}{c}3,25 \\
(2-5,5)\end{array}$ & $\begin{array}{c}4 \\
(2-7)\end{array}$ & $\begin{array}{c}4,25 \\
(2-7,5)\end{array}$ & $<0,001^{*}$ \\
\hline $\begin{array}{l}\text { Kekuatan fleksi } \\
\text { pergelangan } \\
\text { tangan }(\mathrm{kg})\end{array}$ & $\begin{array}{c}1,5 \\
(0,5-5)\end{array}$ & $\begin{array}{c}2,25 \\
(1-6,25)\end{array}$ & $\begin{array}{c}2,5 \\
(1-8)\end{array}$ & $\begin{array}{c}3 \\
(1-8,25)\end{array}$ & $<0,001^{*}$ \\
\hline $\begin{array}{l}\text { Kekuatan ekstensi } \\
\text { pergelangan } \\
\text { tangan }(\mathrm{kg})\end{array}$ & $\begin{array}{c}1,75 \\
(0,5-4)\end{array}$ & $\begin{array}{c}2 \\
(0,5-5,5)\end{array}$ & $\begin{array}{c}2,5 \\
(1-6,5)\end{array}$ & $\begin{array}{c}2,75 \\
(1,25-7,5)\end{array}$ & $<0,001^{*}$ \\
\hline $\begin{array}{l}\text { Kekuatan } \\
\text { menggenggam } \\
(\mathrm{kg})\end{array}$ & $\begin{array}{c}3 \\
\left(0,5^{-13}\right)\end{array}$ & $\begin{array}{c}4 \\
(1-14)\end{array}$ & $\begin{array}{c}5 \\
(1-14)\end{array}$ & $\begin{array}{c}5 \\
\left(1,5^{-14}\right)\end{array}$ & $<0,001^{*}$ \\
\hline Skor CAHAI-9 & $\begin{array}{c}47 \\
(16-60) \\
\end{array}$ & $\begin{array}{c}56 \\
(17-61) \\
\end{array}$ & $\begin{array}{c}61 \\
(18-63) \\
\end{array}$ & $\begin{array}{c}63 \\
(20-63) \\
\end{array}$ & $<0,001^{*}$ \\
\hline
\end{tabular}

Keterangan: distribusi data tidak normal sehingga digunakan uji Friedman; tanda * menunjukkan bermakna secara statistik

normal menurut klasifikasi WHO untuk Asia. Hal ini sesuai dengan penelitian Song dkk. ${ }^{20}$ bahwa indeks massa tubuh (IMT) rata-rata pasien strok iskemik berusia $40-64$ tahun adalah $23,1 \mathrm{~kg} / \mathrm{m}^{2}$.

Peningkatan yang bermakna kekuatan AGA setelah latihan sesuai dengan penelitian Carr dan Jones $^{21}$ serta oleh Flansbjer. ${ }^{22}$ Carr dan Jones $^{21}$ mendapatkan peningkatan bermakna kekuatan fleksi dan ekstensi bahu sisi AGA paresis pada pasien strok kronik setelah latihan penguatan mempergunakan dinamometer sebanyak 3 (tiga) kali per minggu selama 16 minggu. Flansbjer ${ }^{22}$ mendapatkan peningkatan bermakna kekuatan fleksi dan ekstensi lutut anggota gerak bawah sisi paresis pada pasien strok kronik setelah latihan penguatan menggunakan dinamometer 3 kali per minggu selama 10 minggu.

Pada penelitian terjadi peningkatan kekuatan fleksi dan ekstensi bahu, fleksi dan ekstensi siku, fleksi dan ekstensi pergelangan tangan, serta menggenggam pada minggu ke-2, ke-4, dan ke6. Hal ini sesuai dengan teori tentang respons tubuh terhadap latihan penguatan, yaitu tubuh akan beradaptasi terhadap latihan penguatan. Pada 6 minggu pertama, peningkatan kekuatan terutama diakibatkan adaptasi neural, kemudian diikuti adaptasi struktural. Setelah 6 minggu, adaptasi neural akan mengalami penurunan dan adaptasi struktural akan mengalami percepatan. ${ }^{23}$ Peningkatan kekuatan setelah latihan 2, 4, dan 6 minggu disebabkan oleh adaptasi neural.

Pada saat adaptasi neural terjadi reorganisasi kortikal, juga peningkatan arus eferen dari pusat supraspinal dan peningkatan eksitabilitas neuron motorik, perubahan aktivitas unit motoriknya, peningkatan aktivasi otot agonis, penurunan kokontraksi otot antagonis, dan cross education. ${ }^{24}$ Proses adaptasi neural diikuti dengan adaptasi struktural, yaitu merupakan peningkatan ukuran penampang melintang otot, hipertrofi serabut otot, pertumbuhan miofibril, hiperplasia serabut otot, serta perubahan tipe serabut otot. ${ }^{25}$

Pada penelitian ini peningkatan kemampuan fungsional dalam keadaan melakukan tugas-tugas 
CAHAI-9 semuanya bermakna secara statistik. Hal ini sesuai dengan penelitian Kwakkel dkk. ${ }^{26}$ bahwa fungsi AGA pada pasien strok meningkat dalam 4 minggu pertama.

Faktor lain yang memiliki kontribusi terhadap peningkatan kekuatan dan fungsi pada penelitian ini adalah subjek penelitian dalam fase subakut. Fase ini penting untuk pemulihan. Pemulihan pada pasien strok terdiri atas pemulihan spontan atau neurologis dan juga pemulihan fungsional atau adaptif. Pemulihan spontan terjadi akibat proses reparasi yang berlangsung segera setelah lesi. Proses ini berupaya mengembalikan fungsi jaringan saraf yang telah mengalami lesi. Pada pemulihan spontan yang dini, terjadi proses lokal berupa resolusi edema di sekitar area infark sehingga fungsi neuron dapat kembali, terjadi reperfusi area penumbra dan resolusi diaskisis. ${ }^{21}$ Pemulihan spontan dini diikuti dengan pemulihan spontan lanjut berupa reorganisasi sistem saraf pusat. Proses yang terjadi pada saat reorganisasi sistem saraf pusat berupa reorganisasi jaringan otak sekitar area infark, aktivitas pada hemisfer ipsilesi, dan aktivitas hemisfer kontralesi. ${ }^{11}$

Mekanisme reorganisasilain dalam pemulihan motorik merupakan peningkatan level aktivitas sensorimotor pada area kontralateral dari sisi lesi. Penelitian pada hewan coba menunjukkan bahwa pada sisi yang kontralateral lesi terjadi pertumbuhan sel dendrit, diikuti sinaptogenesis. Modifikasi aktivasi ini merupakan konsekuensi akibat dari penggunaan yang berlebih (overuse) pada sisi anggota gerak yang sehat. ${ }^{27}$ Pemulihan neurologis, khususnya reorganisasi sistem saraf pusat memiliki peran penting pada pemulihan fungsional. ${ }^{28}$ Untuk terjadi masa reorganisasi yang lebih panjang maka perlu proses motor learning. Motor learning tidak hanya melibatkan penggunaan yang berulang anggota gerak, tetapi pengulangan dalam melakukan tugas fungsional yang bertujuan. ${ }^{28}$ Pada penelitian ini subjek tidak diamati dan tidak dilarang melakukan aktivitas kegiatan yang sehari-hari termasuk melakukan gerakan seperti gerakan dalam tugas fungsional CAHAI. Gerakan-gerakan tersebut merupakan gerakan bertujuan sehingga apabila dilaksanakan berulang-ulang dapat memberi kontribusi pada pemulihan fungsional AGA.

Faktor lain yang memiliki kontribusi pada peningkatan fungsi AGA itu adalah lokasi lesi. Sebagian besar subjek mempunyai lesi pada hemisfer kiri (hemisfer dominan) dan median pada pengukuran skor CAHAI-9 setelah 6 minggu latihan adalah 63. Enam puluh tiga adalah nilai paling tinggi pada skor CAHAI-9. Hal ini sesuai dengan penelitian Kwakkel dkk. ${ }^{26}$ bahwa pasien strok dengan lesi pada hemisfer kiri memiliki pemulihan fungsi AGA lebih baik daripada lesi pada hemisfer yang kanan. Lokasi lesi di kortikal mempunyai prognosis lebih baik daripada lesi subkortikal dan makin posterior lokasi lesi pada bagian posterior kapsula interna maka makin buruk prognosis fungsi AGA. ${ }^{27}$ Pada penelitian ini tidak dilakukan penentuan lokasi tersebut.

Pada penelitian terdahulu oleh Duncan dkk. ${ }^{13}$ latihan penguatan merupakan salah satu dari suatu rangkaian latihan yang dilakukan selama 12 minggu, 3 kali per minggu dengan supervisi, dan di luar latihan subjek melaksanakan latihan penguatan tanpa supervisi. Latihan penguatan menggunakan pita elastik dilakukan pada fleksi dan rotasi eksternal bahu, fleksi dan ekstensi siku, serta ekstensi pergelangan tangan, namun pengukuran kekuatan ditujukan pada kekuatan hanya menggenggam. Kekuatan menggenggam dan kemampuan fungsional meningkat tidak bermakna. Hal ini terjadi kemungkinan karena kekuatan yang dilatihkan tidak sama dengan yang akan diukur. Pada penelitian oleh Winstein dkk. ${ }^{14}$ latihan penguatan meliputi sendi bahu, siku, pergelangan tangan, dan menggenggam sebanyak 5 kali per minggu dalam supervisi dan di luar latihan tersebut subjek melakukan latihan penguatan dengan instensitas yang lebih rendah serta kecepatan lebih tinggi. Subjek tidak hanya dilatih penguatan, namun dilakukan juga latihan tugas fungsional sehingga peningkatan bermakna fungsi AGA dapat dipengaruhi juga oleh latihan tugas fungsional.

Pada penelitian ini latihan yang diberikan hanya latihan penguatan. Pengukuran dilakukan terhadap semua kekuatan pada arah gerak yang dilatihkan sehingga terlihat pengaruh latihan penguatan terhadap kekuatan pada arah gerak yang sama. Latihan dilaksanakan $3 \times$ per minggu dengan supervisi. Di luar latihan itu, subjek tidak melakukan latihan penguatan menggunakan pita dan bola elastik sehingga latihan yang dilakukan sama antara satu subjek dan yang lainnya dan oleh karena itu efek latihan penguatan lain dapat diminimalkan.

Pemulihan fungsional tersebut dipengaruhi oleh pengalaman pasien dalam menggunakan sisi anggota gerak yang mengalami kelemahan. Pada penelitian hewan coba ditemukan bahwa motor learning menghasilkan perubahan morfologi pada korteks motorik. Perubahan morfologi ini berupa bertambahnya sinaps dan cabang-cabang 
dendrit spesifik terhadap area korteks motorik yang distimulasi serta meningkatnya fungsi sensorimotor pada strok iskemi. Pengalaman mengerjakansuatutugasfungsionalmenyebabkan reorganisasi otak dan meningkatkan performa motorik. ${ }^{24,25}$ Pada penelitian ini tidak diamati bagaimana dan sebanyak apa subjek melakukan aktivitas kegiatan sehari-hari yang berpengaruh terhadap fungsi anggota gerak atasnya sehingga masih terdapat kemungkinan bahwa aktivitas kegiatan yang sehari-hari dan melibatkan AGA paresis memengaruhi perubahan kemampuan fungsional AGA. Pengulangan mempergunakan AGA dalam melakukan aktivitas dapat memicu reorganisasi berupa pemetaan sesuai gerak yang dilakukan dan hal ini akan berpengaruh terhadap fungsi AGA yang digunakan. ${ }^{27}$

\section{Simpulan}

Latihan penguatan AGA dengan pita dan bola elastik efektif meningkatkan kekuatan AGA dan fungsi AGA pada pasien strok iskemi fase subakut. Perlu dilakukan penentuan lokasi lesi untuk mengetahui pengaruh lokasi lesi terhadap peningkatan fungsi serta dilakukan pencatatan aktivitas yang sehari-hari dan melibatkan AGA sehingga kita dapat menentukan faktor-faktor yang memengaruhi efek latihan.

\section{Daftar Pustaka}

1. Meretoja A. Perfect stroke: performance, effectiveness, and costs of treatment episodes in stroke (tesis). Helsinki: University of Helsinki; 2011.

2. Fisher M, Norrving B. The International Agenda for Strok. First Global Conference on Healthy Lifestyles and Noncommunicable Diseases Control. 2014.

3. Badan Penelitian dan Pengembangan Kesehatan, Departemen Kesehatan Republik Indonesia. Riset kesehatan dasar (Riskesdas) 2007. Laporan nasional 2007. Jakarta: Departemen Kesehatan Republik Indonesia; 2008.

4. RSUP Dr. Hasan Sadikin. Data rekam medis RSUP Dr. Hasan Sadikin. Bandung: RSUP Dr. Hasan Sadikin Bandung; 2011.

5. Irasanti SN, Azis Y, Sukarya WS. Pengaruh inovasi jasa dan harga terhadap nilai yang dirasakan pasien di Stroke Center RS AlIslam Bandung. GMHC. 2015;3(1):32-9.

6. Cerniauskaite M, Quintas R, Koutsogeorgou
E, Meucci P, Sattin D, Leonardi M, dkk. Quality-of-life and disability in patients with stroke. Am J Phys Med Rehabil. 2012;91(13 Suppl 1):S39-47.

7. Harvey RL, Roth EJ. Stroke: diagnosis and rehabilitation. Dalam: O'Young BJ, Young MA, Stiens SA, penyunting. Physical medicine and rehabilitation, secrets. Edisi ke-3. Philadelphia: Elsevier; 2008. hlm. 443-55.

8. Christiansen $\mathrm{CH}$, Rogers SL, Haertl KL. Functional evaluation and management of self-care and other activities of daily living. Dalam: Delisa JA, penyunting. DeLisa's physical medicine and rehabilitation, principles and practice. Edisi ke-5. Philadelphia: Lippincott; 2010. hlm. 243-79.

9. Harris JE, Eng JJ. Strength training improves upper-limb function in individuals with stroke: a meta-analysis. Stroke. 2010;41(1):136-40.

10. Harris JE, Eng JJ. Paretic upper-limb strength best explains arm activity in people with stroke. Phys Ther. 2007;87(1):88-97.

11. Harvey RL, Roth EJ, Yu DT, Celnik P. Stroke syndromes. Dalam: Braddom RL, penyunting. Physical medicine and rehabilitation. Edisi ke-4. Philadelphia: Elsevier; 2011. hlm. 1177213.

12. The Hygenic Corporation. Resistance band \& tubing: instruction manual. Acron, Ohio: The Hygenic Corporation; 2012.

13. Duncan P, Studenski S, Richards L, Gollub S, Lai SM, Reker D, dkk. Randomized clinical trial of therapeutic exercise in subacute stroke. Stroke. 2003;34(9):2173-80.

14. Winstein CJ, Rose DK, Tan SM, Lewthwaite R, Chui HC, Azen SP. A randomized controlled comparison of upper-extremity rehabilitation strategies in acute stroke: a pilot study of immediate and long-term outcomes. Arch Phys Med Rehabil. 2004;85(4):620-8.

15. American College of Sports Medicine (ACSM). ACSM's guidelines for exercise testing and prescription. Edisi ke-8. Philadelphia: ACSM; 2010.

16. Koton S, Schneider AL, Rosamond WD, Shahar E, Sang Y, Gottesman RF, dkk. Stroke incidence and mortality trends in US communities, 1987 to 2011. JAMA. 2014;312(3):259-68.

17. Siddique AN, Nur Z, Mahbub S, Alam B, Miah T. Clinical presentation and epidemiology of stroke: a study of 100 cases. J Med. 
2009;10(2):86-9.

18. Picelli A, Tamburin S, Gajofatto F, Zanette G, Praitano M, Saltuari L, dkk. Association between severe upper limb spasticity and brain lesion location in stroke patients. Biomed Res Int. 2014;2014:162754.

19. Gjelsvik BEB, Strand LI, Naess H, Hofstad H, StureSkouen J, Eide GE, dkk. Trunk control and lesion location according to Alberta stroke program early CT score in acute stroke: a cross-sectional study. Int J Phys Med Rehabil. 2014;S3:001.

20. Song YM, Sung J, Davey Smith G, Ebrahim S. Body mass index and ischemic and hemorrhagic stroke: a prospective study in Korean men. Stroke. 2014;35(4):831-6.

21. Car M, Jones J. Physiological effects of exercise on strok survivor. Top Stroke Rehabil. 2003;9(4):57-64.

22. Flansbjer UB. Strength training after stroke: effects on muscle function, gait performance and perceived participation (tesis). Lund, Sweden: Lund University; 2006.

23. Kraemer WJ. Adaptations to resistance training. Dalam: Ehrman JK, deJong A, Sanderson B, Swain D, Swank A, Womak
C, penyunting. ACSM's resource manual for guidelines for exercise testing and prescription. Edisi ke-6. Philadelphia: Lippincott Williams \& Wilkins; 2010. hlm. 489-508.

24. Kidgell DJ. Physiological studies investigating neurological adaptations to resistance training (disertasi). Melbourne: Institute of Sport, Exercise and Active Living, Victoria University; 2010.

25. Folland JP, Williams AG. The adaptations to strength training: Morphological and neurological contributions to increased strength. Sports Med. 2007;37(2):145-68.

26. Kwakkel G, Kollen BJ, van der Grond J, Prevo AJH. Probability of regaining dexterity in the flaccid upper limb: impact of severity of paresis and time since onset in acute stroke. Stroke. 2003;3(9)4:2181-6.

27. Hosp JA, Luft AR. Cortical plasticity during motor learning and recovery after ischemic stroke. Neural Plast. 2011;2011:871296.

28. Krakauer JW. Arm function after stroke: from physiology to recovery. Semin Neurol. 2005;25(4):384-95. 